\title{
AN EXPERIMENTAL STUDY OF THE PHARMACOLOGY OF ERGOT*
}

\author{
Horatio C. WOOD, Jr., M.D. axd CLARENCE A. HOFER, M.D. \\ PIILADELPIIA
}

This research was started as an investigation of the quality of ergot which is at present on the market, and to find a means of improving it. For the purpose of determining the quality of ergot in the light of the knowledge of the chemistry of this subject, the only method which seemed available was the physiological test; but from the beginning, we were impressed with the desirability of establishing if possible, a chemical method for the standardization of this drug. The biological assay of drugs is commercially possible only for large manufacturing houses, since it involves the necessity of employing a separate expert and even under the best conditions, can never be regarded as more than approximately accurate; whereas the proper chemical test should, at least theoretically, be reliable within a very small limit of error. As a result of our studies, we have finally developed a chemical method for the assay of ergot, which in our opinion, is more reliable than any physiological test for this drug which has ever been suggested. For a proper understanding of the basis of the methods we shall suggest and of the evidence of their reliability, it is necessary that we go into the question of the physiological effect of crgot and of the nature of its active principle. Therefore, we shall divide the paper into four sections: "The Physiology of Ergot," "The Chemistry of Ergot," "The Biological Assay" and "The Chemical Assay." In the two introductory sections, it is not our intention to consider in detail the work which has been done on the physiology and chemistry of this drug, but to present chiefly the experimental results of our own investigations.

\section{THE PHYSIOLOGY OF EIROT}

The use of ergot in medicine may be dated from the paper of Stearns, ${ }^{1}$ in which attention was directed to the stimulating influence of the drug upon the uterine muscles. In $1870 \mathrm{Holmes}^{2}$ demonstrated that the intra-

* A part of the expenses of this research was defrayed by a grant from the American Therapeutic Society.

* From the Laboratory of Pharmacology, University of Pennsylvania.

2. Holmes: Arch. de physiol. norm. et path. 1870, iii.

1. Stearns: New York'Med. Repository, 1807. 
venous injection of the drug gave rise to a marked rise in the bloodpressure, which he attributed to vasomotor constriction. In 1906 Meltzer and Auer found that ergot increased the activity of the intestinal muscles, and in the same year, Dale ${ }^{3}$ showed that a similar effect was exercised on practically all the unstriped museles of the body. There can be

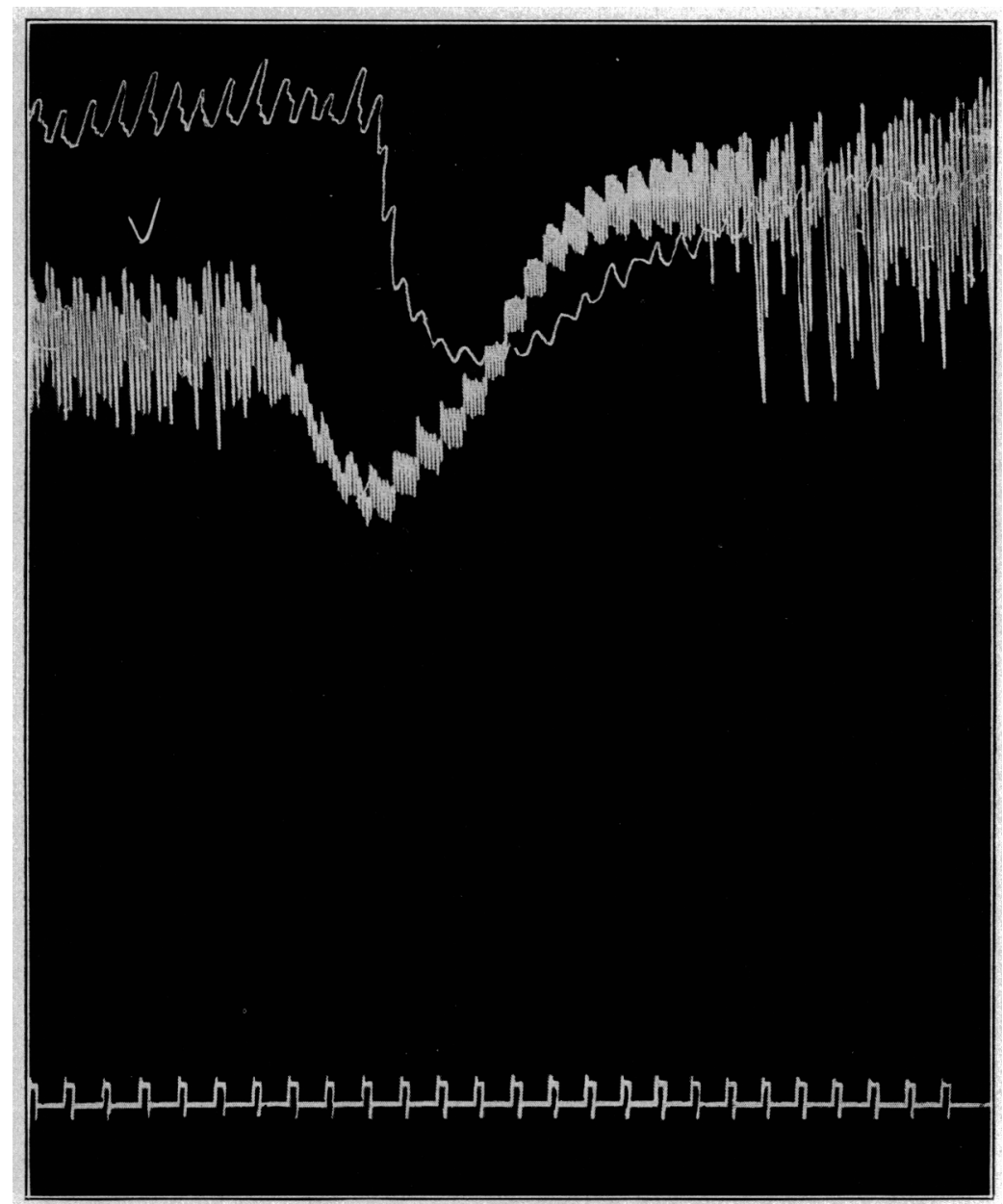

Fig. 1. Showing effect of ergot on blood-pressure and kidney volume. At arrow injection of $0.16 \mathrm{gm}$. per kilo. Time marker $=5$ seconds.

little doubt but that the increased contractions of the uterns and the vasomotor stimulation are part of a wide-spread effect of the drug, involving all involuntary muscle.

3. Dale: Jour. Physiol., 1906, xxxiv, 163. 
There has been some difference of opinion as to whether the stimulant influence on the muscle is the result of an action on the nerve centers or a peripheral effect, either on the terminals of the nerve or the muscle itself. Hemmeter was unable to obtain any evidence of a stimulant
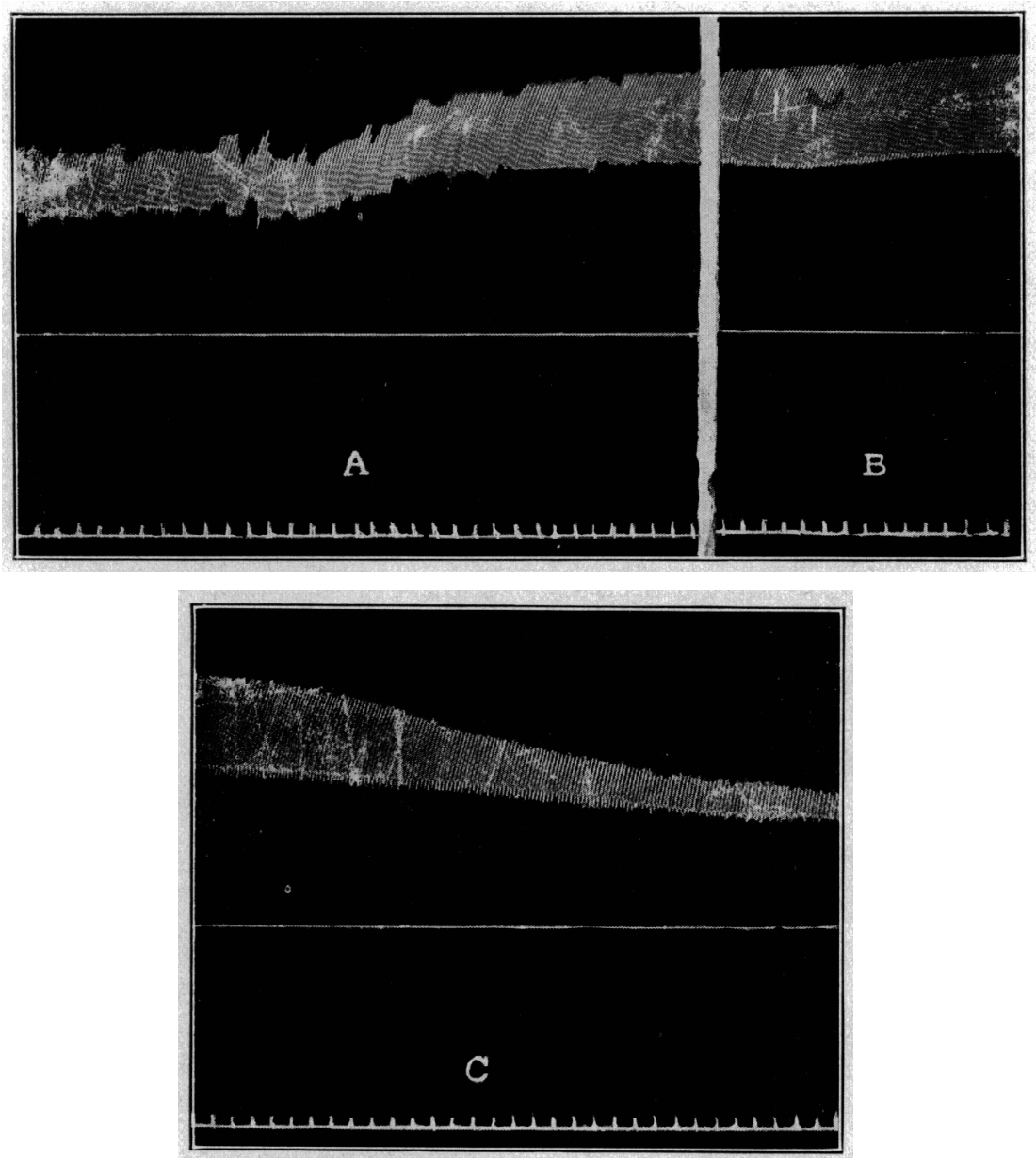

Fig. 2. Showing increase of pulse-pressure caused by ergot. Tracing by Iiirthl's manometer. Both vagi have been eut. At $V$ inject $0.16 \mathrm{gm}$. per kilo. Interval between $A$ and $B$ : 3 minutes $(0.32$ gm: ergot $)$; between $B$ and $C 6$ minutes. Time marker $=2$ seconds.

influence on either the uterus or the vascular system after destruction of the spinal cord; Wood" also reached the conclusion that ergot did not

4. Hemmeter: Med. News, Philadelphia, 1891, lxii.

5. Wool: Philadelphia Med. Times, 1874 , iv. 518. 
produce a rise of pressure after destruction of the vasomotor centers. These authors concluded, therefore, that the action of ergot was central. On the other hand, the experiments of Dixon, of Dale and others seem to demonstrate clearly that the destruction of the medulla does not prevent the action of the drug on the circulation, and Kehrer found that isolated strips of uterine muscle were stimulated by ergot.

In our own experiments, we have found that the rise of pressure after destruction of the vasomotor centers was even greater than in the normal animal. For the purpose of excluding central vasomotor effects, we have used two methods which yielded similar results. The first is the common method of cutting the spinal cord in the cervical region, and the second, which we prefer because there is no loss of blood, is that described in a paper by $\Lambda$ sher and $W o o d,{ }^{7}$ of injecting paraffin into the internal carotid artery with sufficient force to block the circle of Willis and the vertebral arteries, so that the vital centers are killed by acute anemia. In Table 1 are presented the results of two of these experiments.

Most authors have laid considerable stress on the primary lall of blood-pressure which occurs after the intravenous injection of a preparation of ergot, and Holmes attempted to argue from this the occurjence of constriction of the pulmonary vessels.

Table 1.-Resclts of Two Experinexts ox EfFect of frgot on Circllation, Exchloixg Cextral Vasomotor EFfects

Time.* Pressure. nxperimist 1,--Paraffined medella

$\begin{array}{rrc}0 & 73 & \text { Inject } 0.30 \mathrm{gm} \text {. per kilo fluidext. ergot Squibb No. } 2 \\ 2 & 153 & \\ 5 & 184 & \\ 10 & 167 & \\ 25 & 143 & \text { Post-mortem showed circle of Willis and both vertebral arteries } \\ \ldots & \ldots & \text { completely filled with paraffin. }\end{array}$

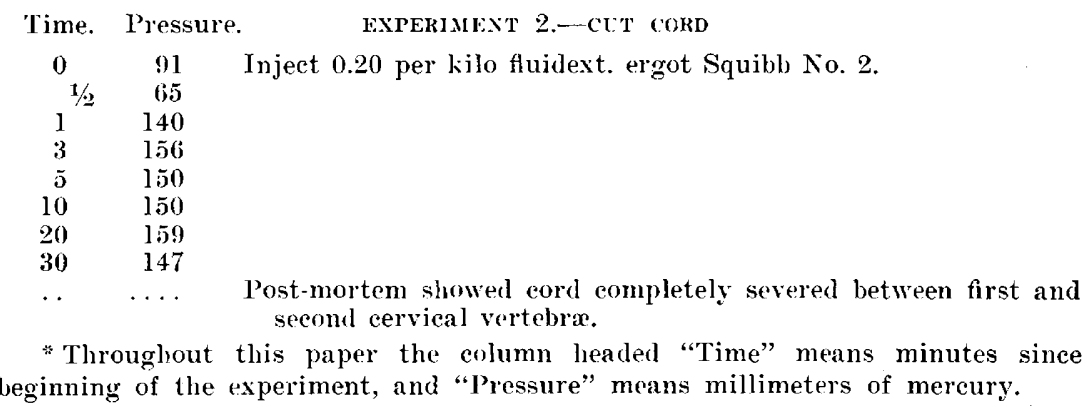

6. Kehrer: Arch. f. exper. Path. u. Pharmakol., 1909, xlix, 266.

7. Asher and Wood: Ztschr. f. Biol., 1899, xix, 307. 
In our experiments, the primary fall of blood-pressure has not been a constant phenomenon. We have obserred it frequently and almost regularly with doses equiralent to more than $0.3 \mathrm{gm}$. per kilo. When, however, the dose does not exceed 0.16 the pressure-fall aimost never occurs, and after hyporlermis administration of the drug, we have not observed it. In our opinion, it cannot be regarded as a part of the physiological action, but is really a poisonous effect from the use of too large doses.

Our plethysmographic studies have shown a contraction of the ressels of the kidney and an enlargement of those of the limb. The latter does not always oceur and is probably passive in origin, due to the blond forced out of the more powerful vascular areas by the high pressure.

Recently Dixon has stated that ergot has a stimulant influence on the rardiac muscle as well as upon the arterial muscles. The article in which we saw this statement contains no experimental evidence of its truth and we have been unable to find the data on which the conclusion is based. We are, howerer, inclined to accept its truth, although our experimental data on the point are not conclusive. Alter section of the pnemogastrice nerve, we find that the pulse-pressure as measured by a Huirthl manometer is very greatly increased by the physiological dose of the drug, and that after toxic doses, the size of the pulse-wave increases and decreases as the blood-pressure ascends and, later, falls. We have attempted to confirm this belief by studies on the isolated heart, but our result: so far, lave not been definitive.

One other foint, which requires mention as bearing on the elaboration of a means of physiological assay, is the duration of the vasomotor constriction. (Tronyin and Henderson * state that the most prolonged rise of blood-pressure they have ever observed following the injection of ergot, lasted but forty minutes; we have, howerer, in a number of experiments, found the effects to last much longer. The longest we have observed is a little over two hours, but as the experinent was not continued and the pressure was still decidedly above the normal, it is fair to conclude that the effect is an enduring one. Our explanation of the comparatively short duration of the raseular stimulation sometimes encountered is improper dosage. If the dose be too small, it is evident that we cannot expect the full physiological action of the drug. and on the other hand, if the dose is too large, the toxic depressant action becomes manifest and forces the blood-pressure down. In the latter instanee, the pressure generally, but not always, falls decidedly below the normal.

\footnotetext{
* Cronyn and Ifenderson: Jomr. Pharmacol, and Hxper. Therap., 1909, i, 203.
} 


\section{ACTIVE PRINCIPLE}

It is not our intention to go into the history of the search for the active principle of ergot, as it has been well summed up by a number of previous writers, but only to mention briefly a few points which bear directly on certain new facts which we have to offer on this subject.

In $18 \%$, Tanret ${ }^{8}$ described a crystalline alkaloid which he named ergotinin. 'This was subsequently, however, shown to be physiologically inert. In 1884, Kobert ${ }^{9}$ ascribed the activity of ergot to two principles, one of which was a resinous acid which he called sphacelinic acid, and the second an alkaloid to which he gave the name of cornutin. (It may be noted in passing that the cornutin of Keller is an cntircly different body, probably a mixture of ergotinin and hydro-ergotinin). More recent investigations, however, have thrown doubt on the natural oceurrence of cornutin, and it is probably a decomposition product, which does not occur as such in ergot; and sphacelinic acid is not a pure proximate substance. Jacobi10 found in ergot a non-nitrogenous body which was neither an acid nor a glucosid, and was highly active physiologically. This body, to which he gave the name of sphacelotoxin, he regarded as the active ingredient of Kobert's sphacelinic acid. He believed that it was found in ergot in the form of two loose combinations, in one with an acid body (chrysotoxin), in the other with an alkaloid (secalintoxin). In 1906 appeared two articles, one by Kraft, ${ }^{11}$ the other by Barger and Carr, ${ }^{12}$ describing a new alkaloid, to which the latter investigators gave the name of crgotoxin, but which Kraft showed to have the same empirical formula as ergotinin plus one molecule of water, and therefore named hydro-ergotinin. Barger and Dale, ${ }^{13}$ in their earlier communications claimed that the activity of all the substances which had been suggested as the active principle of ergot was due to contamination of these substances with ergotoxin which is an extremcly powerful stimulant. Recently, however, they have found that para-hydroxyphenylethylamin, a principle which Barger and Walpole had previously separated from putrid meat infusions, occurs in ergot and has a similar action to the iydro-ergotinin. The substance clavin, isolated by Vahlen ${ }^{14}$ and claimed by this investigator to be a uterine stimulant, has been shown by Dale and also by Cushny, ${ }^{15}$ to be inert.

8. Tanret: Compt. rend. Soc. biol., 1875, lxxxi, 896.

9. Kobert: Arch, f. exper. Path. u. Pharmakol,, 1884, xviii, 316.

10. Tacobi: Arch. f, exper. Path. u. Pharmakol., 1897, xxxix, 85.

11. Kraft: Arch. d. Pharm., 1906, ecxliv, 336.

12. Barger and Carr: Jour. Chem. Soc., 1907, xci, 337.

13. Barger and Dale: Jour. Physiol., 1909, xxxviii.

14. Vahlen: Arch. f. exper. Path. u. Pharmakol., 1908, 1x, 42.

15. Cushny: Jour. Physiol., 1906, xxxv, 1. 
The two substances which seem to us to have the best claims to be regarded as the active principle of ergot are Jacobi's sphacelotoxin and hydro-ergotinin (ergotoxin). Barger and Dale strongly contest the claim of Jacobi that sphacelotoxin is a chemical individual. They assert that the activity of this resinous body is due to contamination with the alkaloid ergotoxin (hydro-ergotinin); although Jacobi claimed to have isolated a small quantity of sphacelotoxin free from nitrogen, and physiologically active, the evidence brought forward to demonstrate the absence of nitrogen is not accepted by the English investigators, and we nust

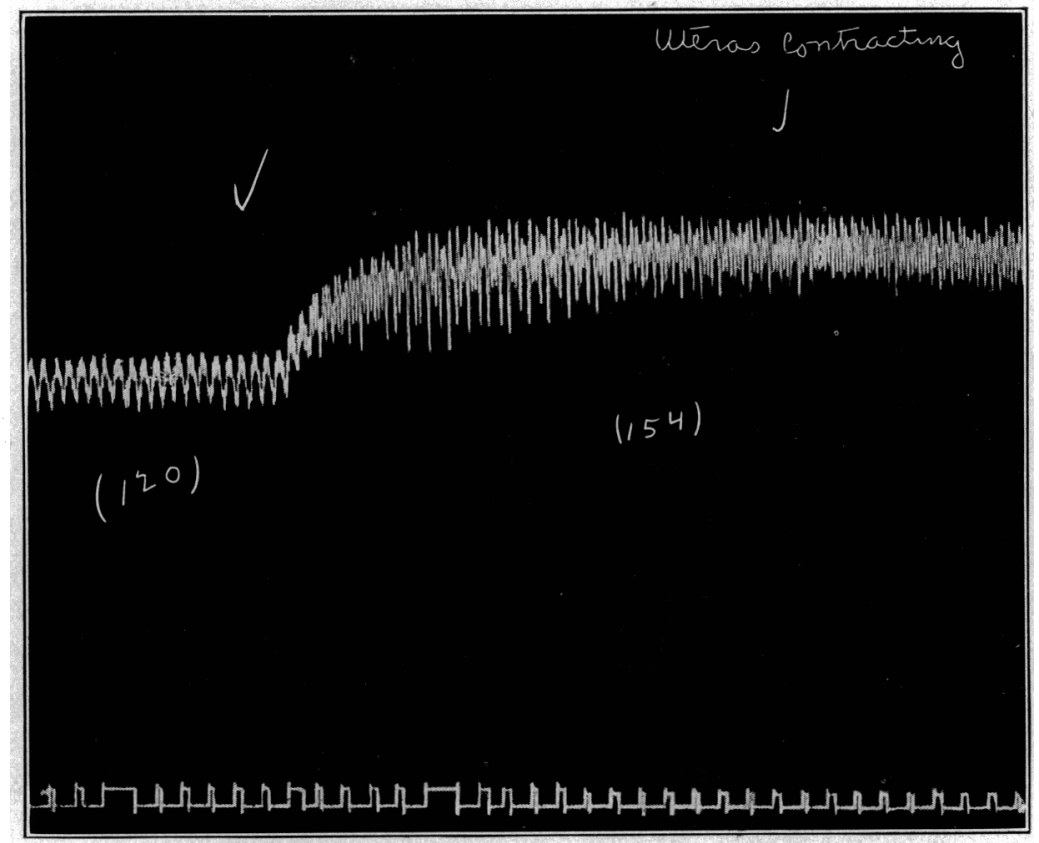

Fig. 3. Showing activity of body extracted by benzol from ergot. At $V$ injection of $0.001 \mathrm{gm}$. per kilo. Time marker $=5$ seconds.

confess that our views agree with those of Barger and Dale. 'The quantity of nitrogen in sphacelotoxin according to our experiments is approximately 1.3 per cent., and with the extremely small quantities of the principle with which Jacobi was working, it is entirely possible that the nitrogen might have been overlonked.

We have separated from ergot by means of benzol, a body of great potency, a dose of $0.0006 \mathrm{gm}$. per kilo being sufficient to cause a distinct rise of blood-pressure. On account of the large amount of fatty matter 
in crude ergot, we have found it more advantageous first to extract with dilute alcohol, precipitate the resinous matter from this fiuidextract with water and then to extract this prceipitate with benzole. The body which we have separated by this process is of an amber yellow color, soluble in acetone, ether, ethyl acetate, chloroform, alcohol, benzol, alkalics and strong mineral acids; insoluble in petroleum benzin, water or dilute acids. If its alkalin solution be acidulated, a turbidity is produced, but the precipitate is no longer soluble in benzol, showing that some chemical change has occurred during its union with the alkalies. When boiled in a porcelain dish with sodium hydroxid, a cherry red color appears at the edge of the liquid. With ferric chlorid, it yields, when fresh, a bright green color and, after keeping, a brownish color. The solution in dilute alcohol, when kept for a few days, becomes a grass-green color. It contains about 1.3 per cent. of nitrogen. By prolonged shaking with acidulated water, it yields to the latter a substance which is precipitated by Mayer's reagent and the other alkaloidal precipitants. If the extraction of a benzol solution of this body with a 1 per cent. hydrochloric acid solution be continued until the aqueous shakings no longer respond to Mayer's reagent, the resin-like body that is left behind is physiologically inert, and contains no nitrogen. The nitrogenous body separated by this process represents about 9 per cent. of the original substance and is extraordinarily active, and responds to the usual tests for alkaloids.

It seems to us improbable that the resin and alkaloid which compose this body are simply mixtures. It will be remembered that Knebel ${ }^{16}$ showed that caffein did not exist, in kola-nut as free caffein, but in the form of a glucosid, to which he gave the name kolanin, which on decomposition yielded the alkaloid, glucose and an inert substance. A similar state of affairs is the most plausible explanation of the close correspondence that we hare found between the physiological activity of a specimen of ergot and the proportion of this body contained in it. 'This fact will be considered in more detail later in the paper.

Although the lack of definite statement by Jacobi as to the chemical properties of his sphacelotoxin, and his unfortunately indefinite use of the terms chrysotoxin and sphacelotoxin, makes it impossible to assert positively the identity of sphacelotoxin and the substance we have separated by means of benzol, yet the fact that the two have the same range of solubilities, that they both turn green on standing, and that their physiological powers are at least comparable in degree, justifies us, we believe, in applying the term sphacelotoxin to this substance. As regards

16. Knebel: Die Bestandteile der Kolanuss, Frankfurt, I892. 
the nitrogenous body which we have separated from our sphacelotoxin, we see no reason to doubt its identity with hydro-ergotinin (ergotoxin). In this connection it is interesting to note that in Dale's experiments, a dose of $1 / 3 \mathrm{mg}$. per kilo in a cat produced a marked rise of bloodpressure with vasomotor reversal; while our alkaloid produced in a dog in a dose of $1 / 6 \mathrm{mg}$. per kilo, a sustained rise of $34 \mathrm{~mm}$.

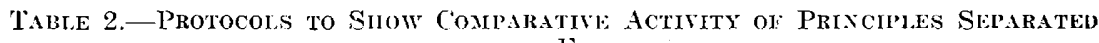
FROM FRaO

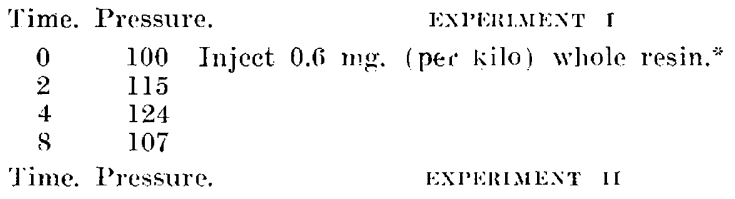

* For convenience, the body extracted from ergot by benzol is referred to as "whole resin," although it must be remembered that it is not all the resinous matter of the drug. 'The term "alkaloid" indicates the nitrogenous body separated from this resin and "washed resin" the inert material left after separating the alkaloid.

\section{BIOLOGICAL ASSAY}

'The first effort to standardize preparations of ergot by physiological means was made by Grïnfeld, ${ }^{17}$ who used the method devised by Kobert, based on the mortification of the comb and wattle of the rooster after large injections of this drug. The method, however, was not generally used for several years, until Houghton ${ }^{18}$ published the results of some commercial applications in 1898 , since which time it has been freely employed.

17. Grïnfeld: Arb. d. Pharmakol. Instit. Dorpat, 1895, xi-xii, 295.

48. Houghton: 'Therap. Gaz., 1898. xiv, 433. 
The theory of the cock's-comb test was that the ergot caused a violent cortraction of the arteries, preventing the circulation in the comb and thus leading eventually to a dry gangrene. although as at present applied the final reaction is only transient darkening in color. There is, however, no convincing evidence that the interruption of the circulation is due to arterial spasm. If it were, one would expect an ischemia rather than a congestion. The fact that much larger doses are required to cause the bluing of the comb than are required to produce constitutional symptoms shows that the effect is a violent toxic one rather than a physiological one. According to our experience, one-third of the quantity which is needed to cause the least perceptible change in the comb is sufficient to cause diarrhea, that is, to stimulate intestinal peristalsis in the chicken, and if the relative susceptibility of the intestinal tract and the vasomotor system is the same as in the mammal, this dose would carry us into the toxic stage of circulatory depression. Ton Recklinghausen ${ }^{19}$ has shown that the cause of the gangrene is the formation within the arteries of a lyaline plug, but Kobert argned that this thrombus is formed on account of the slowing of the blood stream during the vascular spasm. This view, however, seems hardly tenable in the light of the experiments of Filinger, ${ }^{20}$ who produced similar changes in the cock's comb with cantharides and it scems to us that Ellinger's argument is reasonable that the formation of the thrombus is due to an irritant action on the intima.

From a practical standpoint the fifty experiments on the rooster which we have made have convinced us that this method of assay is too iraccurate to be of utility. In the first place, the individual susceptibility of different chickens is so great that the same animal must be used for comparative experiments with a standard preparation of the preparation to be tested. If this is done, it is evidently essential that the dose must not be large enough to cause permanent changes in the circulation of the comb; but lesser degrees of congestion are so difficult of comparison that it is almost impossible to determine accurately the final reaction. In certain roosters, for some unknown reason, we found it impossible, as have other experimenters, to produce any bluing at all of the comb or wattle. In one chicken that we experimented on. a dose of 2.1 c.c. of fluidextract of ergot gave rise to distinct constitutional symptoms, consisting of diarrhea, rapid breathing and excitement; the comb did not become bluish but seemed a little paler than normal. Larger doses produced more marked constitutional symptoms and a more pronounced blanching of the comb, but although we gave as high as 30 c.c.

19. Von Recklinghausen: Handluch der allgemeinen Pathologie, 1883, 349.

20. Ellinger: Arch. f. exper. Path. u. Pharmakol., 1908, lviii, 437. 
of the same preparation, no darkening of the comb occurred. It is of interest to note that two weeks after this last dose, the crop of the chicken separated as a dry, hard, blackish mass without suppuration. Grünfeld, as well as later investigators, has mentioned this local mortifying effect at the point of introduction of the drug whether administered by the mouth or hypodermically. The point we wish to bring out is that in two of three instances of local gangrene in our experiments, there was no gangrene of the comb or wattle.

On account of the uncertainty of the cock's-comb reaction, we have not attempted to make any comparative tests with this and other methods of assay. Edmunds, however, experimented with a preparation which produced a typical reaction in the rooster but was inert when tested on the uterus.

In 1908, Edmunds ${ }^{21}$ published a method of assay, based on the quantity of ergot required to produce contractions in the uterus of a cat. We believe, that with proper precaution, this method would be capable of giving reliable results, but there are a number of factors which make it, in our opinion, less desirable than the one we have to suggest. There are three objections to this method which seem to us of practical importance: In the first place, there is no distinct end-reaction to show how vigoroue shall be the uterine contractions which will indicate the action of the drug; secondly, it has been proven that there is a distinct difference in the susceptibility of the multiparous and nulliparous uterus; and finally, it doubles the difficulty of obtaining test animals.

We may mention one other method, which has been used by Dale, in testing certain preparations from ergot. The Dale method is based on the obscrvation that after the injection of certain principles derived from ergot, a dose of adrenalin causes a fall of blood-pressure instead of a rise; this he calls the rasomotor reversal. 'This vasomotor reversal is apparently not characteristic of ergot itself; Cronyn and Henderson found, as did we, that using the crude drug, the action was extremely uncertain. It is, therefore, not available for standardizing ergot.

We have used a method based upon the amount of elevation of the blood-pressure caused by the injection of a standard dose of ergot. ${ }^{22}$ The

21. Edmunds, C. W., and Roth. G. B.: Plysiologic Assay of Nitroglycerin Tablets, Digitalin Tablets and Fluidextract of Ergot, Jour. Am. M[ed. Assn., 1908, li, 2130.

22. Since writing this paper we have seen a brief article published in 1905 (Pharm. Jour. and Tr., 1905, lxxv, 157), of which we were previously unaware, by W. E. Dixon, containing the statement that he found the effect on blood. pressure to be a satisfactory means of standardizing ergot, but does not describe the details of the method employed. This communication of Dixon's antedates our first paper on this subject more than three years. 
objection which las been raised against vasomotor tests of the drug on the ground that it is mere assumption to claim that a specimen active in regard to the circulation is equally so to the uterus, is, in the light of recent research, untenable. As has been shown above, the characteristic effect of ergot is a stimulation of all unstriped muscle tissue of the body, and the changes in the circulation, in the intestines and in the uterus are but a part of one general action. All of those substances which have been suggested by rarious wuiters as the active principle of ergot hare produced stimulation of blood-ressel as well as uterus, with the exception of Vahlen's clavin, which there is strong reason to believe is not active. From a scientific standpoint there is no choice between a uterine and circulatory test for the drug; the preference must be made on purely utioitarian lines; which is the simpler and which rields the most reliable results. We shall consider the accuracy of results after description of our method.

The first thought in estimating the strength of the drug through its effects upon the circulation would be to compare the effects of the speciinen being tested with the effects of a standard preparation in the same animal, as is done, for instance, with adrenalin. This in the case of ergot, however, is impossible because the drug lingers for so long in the system. We have already noted that the blood-pressure may remain high for at least two hours after the injection of a single dose, but even after the pressure las returned to the normal apparently there still remains some of the drug in the system, for we have found that the effects of a second dose of the same preparation cannot be compared to the effects of the first dose even if the pressure has returned to normal in the interval between the two injections. In all the experiments quoted in this paper we have considered only the effects of first doses.

Another method which would scem obvious, would be to ascertain the amount of drug necessary to produce a certain arbitrary rise in the bloodpressure in a series of animals. Our early experiments were carried out with this idea, but we were forced to abandon it because certain samples produced no rise at all, but especially because the amount of elevation did not vary according to the size of the dose. A dose of 0.12 gm. per kilo would produce as high a rise as double or treble or even four times this quantity. This point we shall consider later, but we will call attention here merely to Table 3 , which shows the results of some of our carly experiments bearing upon this fact.

Having demonstrated that the degree of action bore no relation to the size of the dose, we next carried out a series of experiments to determine whether the response was constant in different animals for the same dose 
of the same preparation. The idea was to adopt a standard dose and measure the activity of the preparation by the rise of blood-pressure which followed the injection of this quantity.

Table 3.-Explermexts to Show tilat Fffects do Nor Vary with the Dose

\begin{tabular}{|c|c|c|c|c|c|}
\hline \multirow{4}{*}{$\begin{array}{l}\text { Sample. } \\
\text { P. D. No. 1.... }\end{array}$} & Jose per & Maximum & \multirow{4}{*}{$\begin{array}{l}\text { Sample. } \\
\text { H. k. M... }\end{array}$} & Dose per & Maximum \\
\hline & kilo. & rise in $\mathrm{mm}$. & & kilo. & rise in $\mathrm{mm}_{6}$. \\
\hline & 0.10 & 35 & & 0.12 & $\begin{array}{r}6 \\
21\end{array}$ \\
\hline & 0.16 & 75 & & $\begin{array}{l}0.20 \\
0.32\end{array}$ & $\begin{array}{l}21 \\
27\end{array}$ \\
\hline \multirow{3}{*}{ P. D. No. $2 \ldots$} & 0.13 & 25 & \multirow{3}{*}{ Lilly } & 007 & 24 \\
\hline & 0.24 & 20 & & 0.24 & 12 \\
\hline & 0.48 & 20 & & 0.41 & 41 \\
\hline
\end{tabular}

$\begin{array}{lllll}\text { Squibl No. } 1 \ldots & 0.14 & 24 \\ & & 0.29 & 62 \\ & & 0.33 & 44 \\ & & 0.34 & 52 \\ & & 0.35 & 45\end{array}$

After some twenty experiments, we came to the conclusion that although there was some general agreement in the amount of elevation of the pressure, it was not close enough to be satisfactory for quantitative work (see Tables 3 and 4). A close examination of our tracings, however, showed that in those instances in which the pressure had ascended abnormally high it was not so well sustained as in those in which the first rise had been less striking; in other words, there was a tendency for a closer correspondence some time after the injection of the drug than immediately after. Our experience led us, in a previous paper, ${ }^{23}$ to adopt, empirically, ten minutes after the injection as the period yiclding the most constant results. Since the publication of this communication, however, further evidence has convinced us that it is necessary to take into consideration the total rise over the whole ten minutes, so that at present our figure of physiological activity is obtained by using the primary rise which follows immediately after the injection and the elevation at five and ten minutes after the injection respectively, and taking the average of the three figure: which gives us approximately the average ise for ten minutes after the injection.

Table 4.-Showisg tue Maximcm Rise Pronuced my Doses of 0.33 gM. Per Kino

$\begin{array}{ccc}\text { P. D. No. 2. } & \text { Squibb No. 1. } & \text { S. K. F. Yo. } 1 . \\ 70 \mathrm{~mm} . & 47 \mathrm{~mm} . & 40 \mathrm{~mm} . \\ 27 \mathrm{~mm} . & 45 \mathrm{~mm} . & 50 \mathrm{~mm} . \\ 75 \mathrm{~mm} . & 50 \mathrm{~mm} . & 65 \mathrm{~mm} . \\ 57 \mathrm{~mm} . & 62 \mathrm{~mm} . & \\ 89 \mathrm{~mm} . & 55 \mathrm{~mm} . & \\ 57 \mathrm{~mm} . & 42 \mathrm{~mm} . & \end{array}$

23. Wood and Hofer: Liniv. Penn. Med. Bull, 1909, xxi, 348. 
In Table 7 are the results of eighty-four tests of twenty-two samples of ergot. It will be noted in this table, that in 55 per cent. of the experiments, the average rise is within $5 \mathrm{~mm}$. of the average for the whole series with each preparation. For instance, with preparation Squibb No. 2, there are five tests, and of these, the average of the whole group being $36.6 \mathrm{~mm}$., the lowest rise was 28 and the highest was 42 while the other three were less than $4 \mathrm{~mm}$. from the total average of the series. If we extend the limit of error to $10 \mathrm{~mm}$. departure from the average, only 20 per cent. will be outside the limit. It is evident, therefore, that where we have three closely agreeing results, the average of the series will almost certainly be within $5 \mathrm{~mm}$. of the theoretically correct figure for that specimen.

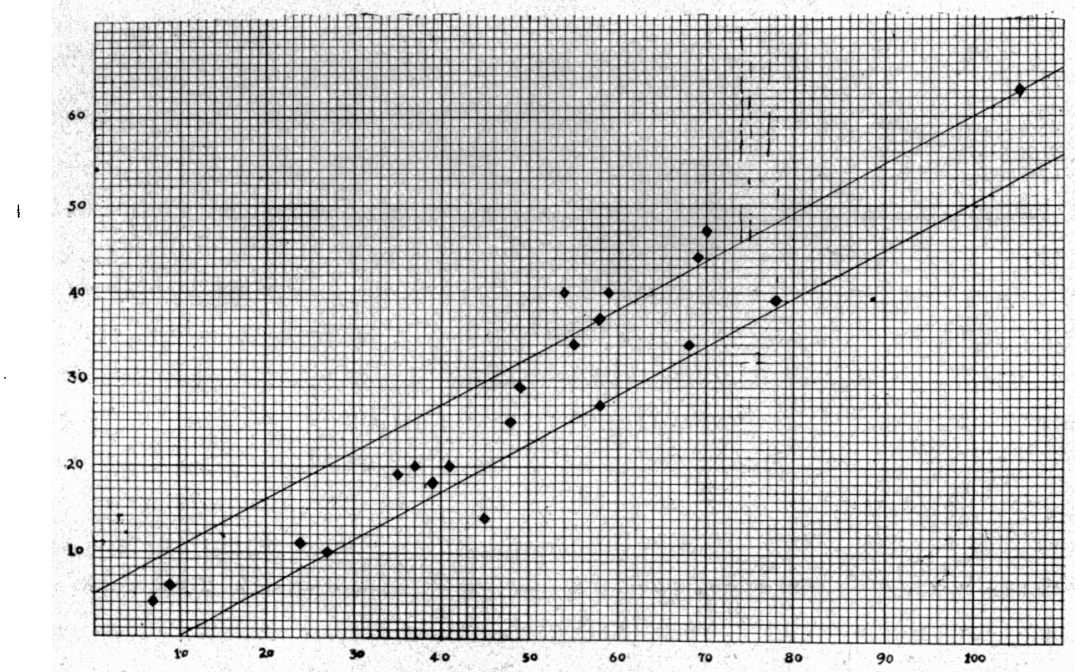

Fig. 4. Results of comparative physiological and chemical assay of various samples of ergot. Figures on abscissa $=$ parts sphacelotoxin per 10,000; figures on ordinate $=$ rise of blood-pressure in millimeters of mercury. Oblique lines represent variations of $5 \mathrm{~mm}$. in the rise of pressure.

One surprising fact is that the activity of the specimen bears no relation to the size of the dose which is required to produce the maximum rise for that sample; the rise of pressure caused by any specimen of ergot is just as great after an eighth of a gram per kilo as after a fourth or even a half, no matter whether we are dealing with an inert or highly active sample. This is apparently so contrary to the accepted laws of pharmacology that we were very loath to believe it, but our experience, rovering now some two hundred tests, allows in our mind no doubt. 
The truth of this statement may readily be seen by referring to Table 4 . For instance, in preparation marked Squibb $\mathrm{Nn}, 2 \mathrm{~F}$., we have doses ranging from 0.13 to $0.20 \mathrm{gm}$. per kilo; the highest pressure in this instance being produced by the smallest dose. In sample marked Retail No. 1 , the doses range from 0.13 to 0.25 and the effects in each instance are practically identical. With retail sample No. 2 , although the dose in one instance was as high as $0.55 \mathrm{gm}$., we obtained practically no evidence of stimulation of the rasomotor system. In a fluidextract which was made in our own laboratory, marked in the table Wood No. 1, the effects of $0.16 \mathrm{gm}$. were exactly the same as those of a dose of $0.24 \mathrm{gm}$.

It therefore becomes necessary to determine the dose which will produce the best results in the majority of animals. Of course, there will

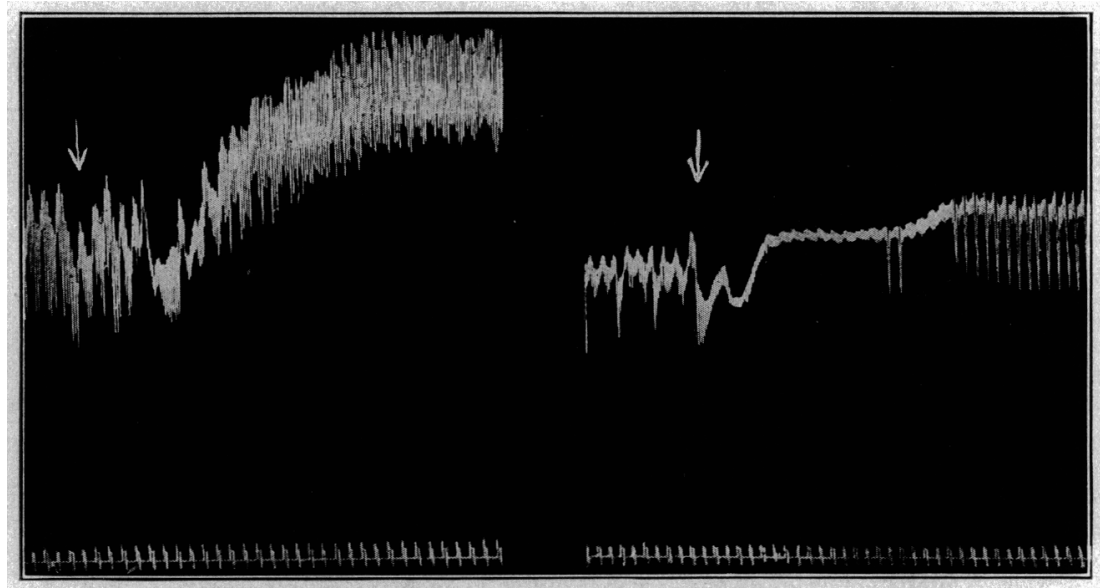

Fig. 5. Showing the deterioration in ergot when improperly kept. The tracing on the left shows the effect of a fluidextract of ergot which had been kept hermetically sealed; the one to the right shows the effect of the same dose of the same preparation after being exposed to the air for 46 days.

be more or less frequent individual variations in the susceptibility of dogs to ergot, so that what is the full physiological dose for one dog may be too small for a second and toxic for a third, but this error can be avoided by a means which we shall mention later. For the present, we wish to determine the dose for the average animal; this must be large enough so that in the majority of cases it will produce the greatest rise possible for that specimen of ergot, and small enough that it will not cause toxic effect in any considerable number of experiments. As evidence of a toxic action, we have taken the fall of pressure to a point 
below normal within a period of ten to fifteen minutes after the intravenous injection of the drug.

We have as available for determining the limit of probable toxicity, the results of 111 experiments which may be tabulated as in Table $\tilde{5}$.

Table 5.-Per Cext. of Toxic Effects After Doses of Varying Sizes

No. experiments. Fall below

normal.

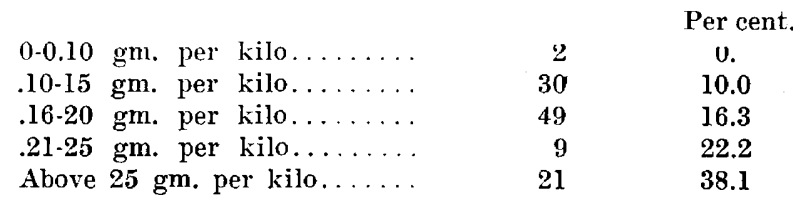

It will be seen that with doses ranging between 0.10 and $0.20 \mathrm{gm}$. per kilo, we have toxic effects in about 13 per cent. of the experiments, and that above the latter limit, the toxic results occur in a much larger number of instances.

To determine the low limit, that is, the smallest dose which is likely to produce the full physiological effect, we have compared the results of a second injection of the same dose at an interval of not less than ten minutes after the first injection. If the blood-pressure is higher above the normal after the second dose than after the first dose, we consider that the full physiological action was not produced by the first dose. We give a table covering the results of 52 experiments bearing upon this point. In this table, it will be noted that with doses of less than 0.10 $\mathrm{gm}$. in every instance the blood-pressure was driven higher by a second dose; while with doses ranging between 0.10 and $0.20 \mathrm{gm}$. in 88 per cent. of cases the first dose produced full physiological action.

It is evident from these two tables that, most generally, efficient doses of ergot will be equivalent to about $0.15 \mathrm{gm}$. per kilo of body weight.

Table 6.--Per Cext. of Ixstaxces ix Which Second Dose Caused a Rise to a Point Higher tilan That Produced by Finst Dose

$0-.10 \mathrm{gm}$. per kilo........

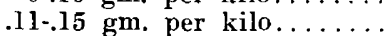

$.16-.20 \mathrm{gm}$. per kilo........

Above 20 per kilo........
No. of experiments. Higher after second dose.

$\begin{array}{rr}4 & 100.0 \% \\ 19 & 26.3 \% \\ 9 & 12.5 \% \\ 20 & 5.0 \%\end{array}$

DESCRIPTION OF METIYOD

Our method as finally worked out is as follows: A dog is given hypodermically from 0.02 to $0.06 \mathrm{gm}$. morphin sulphate according to its size, and after the morphin has had time to act, is tied down and lightly. etherized. The carotid artery is connected with a mercury manometer 
and the jugular vein prepared for injection. The animal is then allowed to recorer from the cther, the blood-pressure not being considered normal until it has remained at a constant level for at least ten minutes after withdrawing the anesthetic. A dose of the preparation under question is then injected, equivalent to approximately $0.15 \mathrm{gm}$. of ergot per kilo and the pressure obscrved for fifteen minutes. At the end of that time, a second dose should be administered in order to ascertain that the full effects have been brought out by the first injection. After watching the effects of the second dose for ten minutes the dog is killed, usually by injerting diloroform into the vein.

To obtain the results which we have described above, there are certain sources of error which experience has tanght us must be sedulous]y avoided. Foremost among these, we wish to emphasize the necessity of the completeness of the recovery from the anesthetic before the administration of the drug. Sot only are there likely to be changes in the blood-pressure during the convalescence from anesthesia, so that it is impossible to establish the norm accurately, but we have found, as have also Cronyn and Henderson, that the effects of ergot are very fre[uently atypical if any large quantity of ether is still circulating in the system. (Whether Henderson's anesthesia by intracerebral injection of magnesinm chlorid would be available for this purpose we cannot say positively but would think it, a priori, improbable). In order to avoid fallacies from ether, we advise that the anesthesia be as light as compatible with prevention of suffering during the operation, and that the blool-pressure be observed at intervals until it has remained at the same revel for ten minutes, before injecting any ergot.

While, of course, the perceptive centers of the dog are much benumber ly the morphin, we have found that in many cases there is a marked circulatory response to psychical influences as shown by alterations in the blood-pressure from whistling or calling. For this reason, complete silence. especially the aroidance of conversation and sulden noises, during the experiment is essential.

Our results in summer indicate strongly that when the room temperature is too lighh. the results are not altogether trustworthy. Into this question we have not gone in detail, but would not have much confidence in assays made in a room with a temperature of more than $25 \mathrm{C}$. ( $\%$ F.)

Screral other factors which are usually believed to have an influence on the effects of drugs deserve a word or two of mention. Age appears to be a factor only in so far that immature animals are more susceptible to the rlug, so that toxic effects are almost the rule with pups. We could oliserve no difference from sex. The sizes of our dogs hare ranged from 
4 to $20 \mathrm{~kg}$. in weight, but with doses proportional to weight, we could see no distinction. The breeds were of all kinds, with a large preponderance of mongrel, the ordinary street dogs of a large city.

Table 7.-Rescits of 84 Tests of 22 SAMples of Ergo'

Preparation. Dose. Squibb No. $1 \ldots$.

$$
\text { sin }
$$

Primary 5 Min. 10 Min. Average

rise. rise. rise. rise.

$\begin{array}{llll}47 & 32 & 2 & 27 \\ 50 & 33 & 8 & 30\end{array}$

$\begin{array}{llll}45 & 33 & 9 & 29\end{array}$

$\begin{array}{llll}47.3 & 32.7 & 6.3 & 28.7\end{array}$

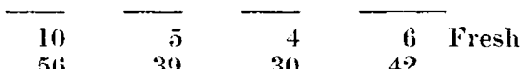

$51 ; \quad 39 \quad 30 \quad 42$

$50 \quad \ldots \ldots \quad 30 \quad 40$

$\begin{array}{llll}50 & \cdots & 30 & 40 \\ 55 & 40 & 25 & 40\end{array}$

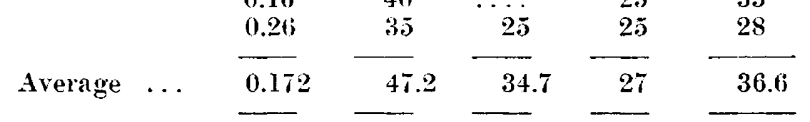

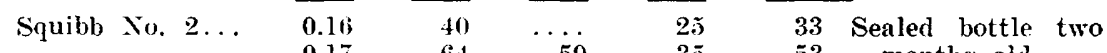

$\begin{array}{llllll}0.17 & 64 & 59 & 35 & 53 & \text { months old }\end{array}$

$\begin{array}{lllll}0.18 & \text { clot } & 32 & 17 & 32\end{array}$

$\begin{array}{lllll}0.18 & 50 & \cdots & 15 & 32\end{array}$

$\begin{array}{lllll}0.18 & 34 & 34 & 25 & 31\end{array}$

$\begin{array}{lllll}? & 75 & \ldots & 25 & 50\end{array}$

Average $\ldots \quad \frac{0.18}{0.175} \quad \frac{90}{58.8} \quad \frac{\cdots}{41.7} \quad \frac{10}{21.7} \quad \frac{50}{40.5}$

$\begin{array}{llllrrr}\text { Squibb No. } 2 \ldots & 0.15 & 15 & \ldots & 0 & 7 & \text { Open bottle two } \\ 0.17 & 51 & \ldots & 11 & 31 & \text { months old }\end{array}$

\begin{tabular}{rrrrrr}
0.17 & 51 & $\ldots$ & 11 & 31 & months old. \\
0.33 & 30 & 21 & 15 & 19 & \\
& - & 23 & 6 & 20 & \\
\hline
\end{tabular}

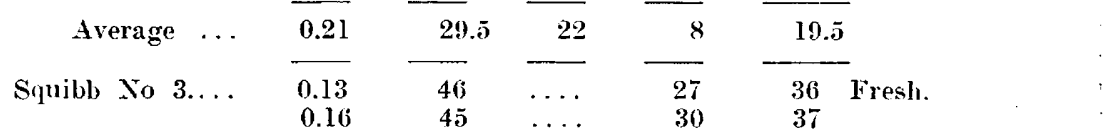

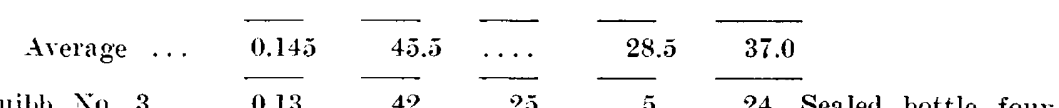

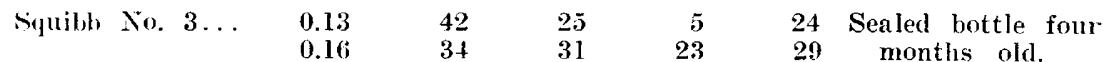

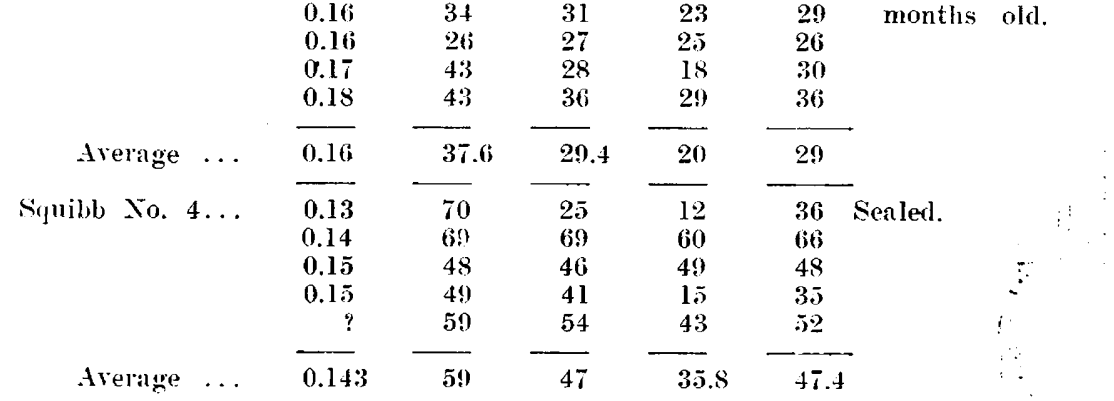


Table \%-Continued

\begin{tabular}{|c|c|c|c|c|c|c|}
\hline Squibb No. $5 \ldots$ & $\begin{array}{l}0.13 \\
0.15 \\
0.18\end{array}$ & $\begin{array}{l}48 \\
79 \\
45\end{array}$ & $\begin{array}{l}33 \\
16 \\
51\end{array}$ & $\begin{array}{l}26 \\
25 \\
35\end{array}$ & $\begin{array}{l}36 \\
40 \\
44\end{array}$ & \\
\hline Average $\ldots$ & 0.153 & 57.3 & 33.3 & 28.7 & 40 & \\
\hline Retail No. 1... & $\begin{array}{l}0.13 \\
0.22 \\
0.25\end{array}$ & $\begin{array}{l}23 \\
35 \\
28\end{array}$ & $\begin{array}{l}20 \\
10 \\
27\end{array}$ & $\begin{array}{l}7 \\
8 \\
9\end{array}$ & $\begin{array}{l}17 \\
18 \\
19\end{array}$ & \\
\hline Average ... & 0.175 & 29 & 19 & 7.5 & 18 & \\
\hline Retail No. $2 \ldots$ & $\begin{array}{l}0.13 \\
0.40 \\
0.55\end{array}$ & $\begin{array}{l}10 \\
10 \\
15\end{array}$ & $\begin{array}{l}0 \\
5 \\
5\end{array}$ & $\begin{array}{l}0 \\
0 \\
0\end{array}$ & $\begin{array}{c}3 \\
5 \\
7\end{array}$ & \\
\hline Average $\ldots$ & 0.36 & 11.7 & 3 & 0 & 5 & \\
\hline S. K. F. No. $1 \ldots$ & $\begin{array}{l}0.14 \\
0.33 \\
0.33 \\
0.51\end{array}$ & $\begin{array}{l}31 \\
50 \\
65 \\
65\end{array}$ & $\begin{array}{l}30 \\
48 \\
65 \\
60\end{array}$ & $\begin{array}{l}28 \\
35 \\
49 \\
40\end{array}$ & $\begin{array}{l}30 \\
44 \\
60 \\
55\end{array}$ & Fresh \\
\hline Average $\ldots$ & 0.328 & 52.8 & 50.8 & 38 & 47.3 & \\
\hline S. K. F. No. $1 .$. & $\begin{array}{l}0.16 \\
0.19 \\
0.19 \\
0.29\end{array}$ & $\begin{array}{l}36 \\
22 \\
26 \\
22\end{array}$ & $\begin{array}{r}22 \\
11 \\
\cdots \\
15\end{array}$ & $\begin{array}{l}16 \\
10 \\
15 \\
12\end{array}$ & $\begin{array}{l}25 \\
14 \\
20 \\
16\end{array}$ & Kept corked. \\
\hline Average $\ldots$ & 0.208 & 26.5 & 16 & 13.3 & 18.8 & \\
\hline S K. F. No. 1. & $\begin{array}{r}0.21 \\
0.22 \\
? \\
? \\
\end{array}$ & $\begin{array}{l}42 \\
30 \\
42 \\
32\end{array}$ & $\begin{array}{l}14 \\
24 \\
31 \\
11\end{array}$ & $\begin{array}{l}20 \\
20 \\
20 \\
10\end{array}$ & $\begin{array}{l}25 \\
25 \\
31 \\
18\end{array}$ & Sealed bottle. \\
\hline Average $\ldots$ & 0.215 & 36.5 & 20 & 17.5 & 24.8 & \\
\hline S. K. F. No, 2 . & $\begin{array}{l}0.10 \\
0.14 \\
0.16 \\
0.16 \\
0.16\end{array}$ & $\begin{array}{l}33 \\
48 \\
44 \\
53 \\
58\end{array}$ & $\begin{array}{l}\ldots \\
43 \\
42 \\
36 \\
46\end{array}$ & $\begin{array}{r}6 \\
34 \\
21 \\
8 \\
29\end{array}$ & $\begin{array}{l}19 \\
42 \\
36 \\
32 \\
44\end{array}$ & $\begin{array}{l}\text { Sealed bottle five } \\
\text { months old. }\end{array}$ \\
\hline Average $\ldots$ & 0.155 & 50.8 & 41.8 & 23 & 38.5 & \\
\hline S. K. F. No. $2 \ldots$ & $\begin{array}{l}0.16 \\
0.16\end{array}$ & $\begin{array}{l}30 \\
12\end{array}$ & $\begin{array}{c}13 \\
6\end{array}$ & $\begin{array}{r}11 \\
\operatorname{clot}\end{array}$ & $\begin{array}{r}18 \\
\cdots\end{array}$ & $\begin{array}{l}\text { Open bottle four } \\
\text { months old. }\end{array}$ \\
\hline Average $\ldots$ & 0.16 & 21 & 9.5 & Il & 13.8 & \\
\hline S. K. F. No. $2 \ldots$ & $\begin{array}{c}0.19 \\
?\end{array}$ & $\begin{array}{l}28 \\
34\end{array}$ & $\begin{array}{l}27 \\
30\end{array}$ & $\begin{array}{r}24 \\
3\end{array}$ & $\begin{array}{l}26 \\
23\end{array}$ & $\begin{array}{l}\text { Open bottle one } \\
\text { month old. }\end{array}$ \\
\hline Average ... & 0.19 & 31 & 28.5 & 13.5 & 24.3 & \\
\hline
\end{tabular}


TABLE 7.-Continued

\begin{tabular}{|c|c|c|c|c|c|c|}
\hline Cook No. $1 \ldots$. & $\begin{array}{l}0.14 \\
0.14 \\
0.14 \\
0.16 \\
0.21\end{array}$ & $\begin{array}{l}34 \\
44 \\
30 \\
86 \\
15\end{array}$ & $\begin{array}{c}27 \\
\ldots \\
\cdots \\
\ldots \\
\ldots \\
\ldots\end{array}$ & $\begin{array}{r}18 \\
24 \\
15 \\
66 \\
6\end{array}$ & $\begin{array}{l}26 \\
34 \\
22 \\
76 \\
11\end{array}$ & Fresh. \\
\hline Average & 0.158 & 41.8 & 27 & 25.8 & 33.8 & \\
\hline Cook No. $1 \ldots$. & $\begin{array}{l}0.15 \\
0.16 \\
0.17\end{array}$ & $\begin{array}{l}38 \\
84 \\
63\end{array}$ & $\begin{array}{r}34 \\
74 \\
\ldots\end{array}$ & $\begin{array}{l}\mathbf{1 8} \\
\mathbf{5 3} \\
31\end{array}$ & $\begin{array}{l}30 \\
70 \\
47\end{array}$ & $\begin{array}{l}\text { Sealed bottle one } \\
\text { month old. }\end{array}$ \\
\hline Average $\ldots$ & 0.16 & 61.7 & 54 & 32.7 & 49.0 & \\
\hline Cook No. $1 . .$. . & $\begin{array}{l}0.12 \\
0.13 \\
0.13\end{array}$ & $\begin{array}{l}30 \\
40 \\
52\end{array}$ & $\begin{array}{l}35 \\
39 \\
22\end{array}$ & $\begin{array}{l}38 \\
27 \\
22\end{array}$ & $\begin{array}{l}34 \\
35 \\
32\end{array}$ & \\
\hline Average & 0.127 & 40.7 & 32 & 29 & 33.7 & . \\
\hline Cook No. $2 \ldots$. & $\begin{array}{l}0.17 \\
0.18 \\
0.17\end{array}$ & $\begin{array}{r}37 \\
15 \\
7\end{array}$ & $\begin{array}{r}17 \\
9 \\
2\end{array}$ & $\begin{array}{l}7 \\
6 \\
0\end{array}$ & $\begin{array}{r}20 \\
10 \\
3\end{array}$ & \\
\hline Average $\ldots$ & 0.175 & 19.7 & 9.3 & 4.3 & 11.0 & \\
\hline Wood No. $1 \ldots$ & $\begin{array}{l}0.16 \\
0.17 \\
0.24\end{array}$ & $\begin{array}{l}46 \\
40 \\
45\end{array}$ & $\begin{array}{c}35 \\
30 \\
30\end{array}$ & $\begin{array}{l}22 \\
13 \\
25\end{array}$ & $\begin{array}{l}34 \\
27 \\
33\end{array}$ & \\
\hline Average ... & 0.19 & 43.7 & 32.5 & 20 & 31.3 & \\
\hline Special $\ldots \ldots \ldots$ & $\begin{array}{r}0.14 \\
0.14 \\
0.20 \\
0.23 \\
?\end{array}$ & $\begin{array}{l}15 \\
12 \\
36 \\
37 \\
30\end{array}$ & $\begin{array}{r}4 \\
\ldots \\
20 \\
34 \\
25\end{array}$ & $\begin{array}{r}2 \\
0 \\
16 \\
22 \\
18\end{array}$ & $\begin{array}{r}7 \\
6 \\
24 \\
31 \\
26\end{array}$ & \\
\hline Average $\ldots$ & 0.178 & 20 & 20.8 & 11.6 & 18.8 & \\
\hline
\end{tabular}

The only methods employed for the chemical assay of ergot have been various modifications of that of Keller, which is based on the percentage of total alkaloids present. As far as our reading goes, there is no experimental evidence to show that the figures obtained by Keller's method of assay bear any relation to the physiological activity of different specimens of ergot. The paper of Dohme and Crawford, which is sometimes quoted as demonstrating the value of Keller's test, is open to several serious objections. It really proves nothing beyond the fact that one can obtain from ergot physiologically active alkaloids. Vanderkleed found that the relationship between the percentage of alkaloids and the activity of ergot when tested by the cock's-comb method is extremely 
precarious. It has been pointed out by Barger that the fallacy of Keller's method resides chiefly in the fact that the alkaloids extracted consist of a mixture of the active hydro-ergotinin and the inert ergotinin, and that as there is no method of separating these alkaloids, the resultant figures are untrustworthy.

In the course of our experiments in the biological standardization of ergot, we were struck by the fact that those samples of fluidextract which gave but little precipitate on the addition of water were uniformly of low potency; this led us to investigate the possible relation between the percentage of resinous matters and the activity of the drug. After experimenting with various solvents, we finally decided on the following method: Take 10 c.c. of fluidextract of ergot, add 20 c.c. of water, shake with repeated portions of 10 c.c. each of benzol, until the latter comes away colorless; unite the various portions of benzol in a tared dish. evaporate over a water bath and dry at a temperature of $37 \mathrm{C}$. to constant weight. We may remark in passing that almost uniformly very troublesome emulsions are formed; these can be most readily broken up by the method suggested by Dunn, of adding filter paper to the emulsion.

We have already described the chemical nature and physiological properties of the body which is obtained by benzol extraction. We wish. at this place, simply to emphasize the fact that the benzol extractive does not represent the total resin of ergot; the proportion of the water-insoluble substances which are dissolved by the benzol varies greatly in different specimens.

Whether or not our ideas of the nature of this substance are correct. we are well satisfied that the amount present is an accurate indicator of the activity of the fluidextract of ergot. We give herewith (Tal)le 8) the results of comparative physiological and chemical assays of twenty-one samples of fluidextract, ${ }^{24}$ ranging in physiological activity from 4 to 63 , covering the whole gamut of possible degrees of power. It will be noted that the percentage of benzol extractive increases regularly as the physiological activity becomes greater. There are, as might be expected, one or two slight deviations from mathematical exactitude, but these are mostly well within the limit of error. In the case of the sample marked Special, two of the physiological tests differed very widely from the rest of the series (see Table 8). Excluding those two experiments, the physiological figure would be 27 instead of 19 .

24. The sample labeled Wood No. 2 is a 50 per cent. tincture, but is calculated to correspond to fluidextract strength. 
Table 8.-Results of Comparative Physiological axp Cimmical assays of 21 Samples of Ergot

Preparation.

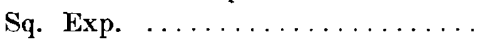

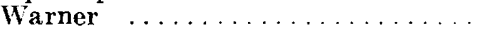

Retail No. $4 \ldots \ldots \ldots \ldots \ldots \ldots$

Cook No. $2 \ldots \ldots \ldots \ldots \ldots \ldots$

S. K. F. No. 1 (C) . . . . . . .

Squibb No. 2 (O) ..............

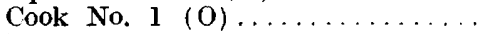

Wood No. $2 \ldots \ldots \ldots \ldots \ldots \ldots \ldots$

S. K. F. No. 2 (O) $\ldots \ldots \ldots \ldots \ldots$

S. K. F. No. 1 (S) . . . . . . . .

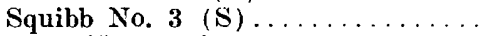

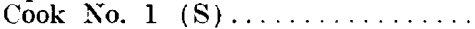

Squibb No. 5.............

Special $\ldots \ldots \ldots \ldots \ldots \ldots \ldots \ldots$

Squibb No. 3 (F) . . . . . . . .

Squibb No. 2 (S) ............

Cook No. 1 (F) ................

Squibb No. 4 (C.) . . . . . . . .

Squibb No. 4 (S) . . . . . . . .

S. K. F. No. 2 (S) . . . . . .

S. K. F. No. $2(\mathrm{~F}) \ldots \ldots \ldots \ldots \ldots$
Per cent. of Rise of

Sphacelotoxin. Blood-pressure.

$\begin{array}{lr}0.07 & 4 \\ 0.09 & 6 \\ 0.27 & 10 \\ 0.24 & 11 \\ 0.35 & 19 \\ 0.37 & 20 \\ 0.39 & 18 \\ 0.42 & 20 \\ 0.45 & 14 \\ 0.48 & 25 \\ 0.49 & 29 \\ 0.55 & 34 \\ 0.54 & 40 \\ 0.58 & 19 \\ 0.58 & 37 \\ 0.59 & 40 \\ 0.68 & 34 \\ 0.69 & 44 \\ 0.70 & 47 \\ 0.78 & 39 \\ 1.05 & 63\end{array}$

For easier comprehension of these results, we have plotted them in a diagrammatic form; in Figure 4, the abscissa represents parts per ten thousand of sphacelotoxin and the ordinate millimeters of rise of bloodpressure. We have drawn on this figure, two parallel lines, representing variations of $5 \mathrm{~mm}$. in the blood-pressure above or below the arerage, which is the limit of accuracy we claim for our method of phrsiological assay. In this figure, four specimens are slightly outside of these limits. Of these, one is the sample labeled in our Table S. K. F. No. 2 (O); of this sample, unfortunately, we have but two physiological tests, and one of these is not complete on account of a clot at the end of the ten minutes, so that we can place comparatively little reliance on the physiological figure. Of the other four samples which fall without the limits mentioned, only one is more than $3 \mathrm{~mm}$. of pressure outside these limits, so we feel justified in claiming that there is a marked degree of parallelism between the physiological activity of the drug and the percentage of sphacelotoxin.

Another fact which is strongly corroborative of the ralue of this method of assay is that in specimens which have deteriorated from long keeping, the diminution in the amount of sphacelotoxin runs closely parallel to the loss of physiological power (see Table 12). Thus, S. K. F. No. 2, when fresh, gave a chemical assay of a little orer 1 per cent. and caused a rise of blood-pressure of $63 \mathrm{~mm}$. A sample of this fluid 
extract kept hermetically sealed, showed six months later a sphacelotoxin content of 0.81 per cent.; the same preparation, left uncorked, fell in its chemical assay from 1.05 to 0.45 , and in its physiological figures from 55 to 13 . Similar parallelism may be noted in the case of Squibb No. 4, Squibb No. 3 and Cook No. 1.

A further confirmation of our beliefs we are enabled to offer through the courtesy of E. R. Squibb and Son. This firm prepared for us two concentrated preparations from the same sample of crude ergot, one of which contained 0.5 per cent. of alkaloid by Keller's method and 0.7 per cent. of sphacelotoxin; the other preparation contained the same amount of alkaloid but yielded 4.0 per cent. of sphacelotoxin. The former preparation, rich in alkaloid, when injected into the dog in doses of $22 \mathrm{mg}$. per kilo, caused a rise of $14 \mathrm{~mm}$. in the blood-pressure, and in a dose of $53 \mathrm{mg}$. gare a rise of but $24 \mathrm{~mm}$. The other preparation, which contained a high percentage of resin, gave in doses of 23 and $29 \mathrm{mg}$., 40 and $45 \mathrm{~mm}$. rise respectively.

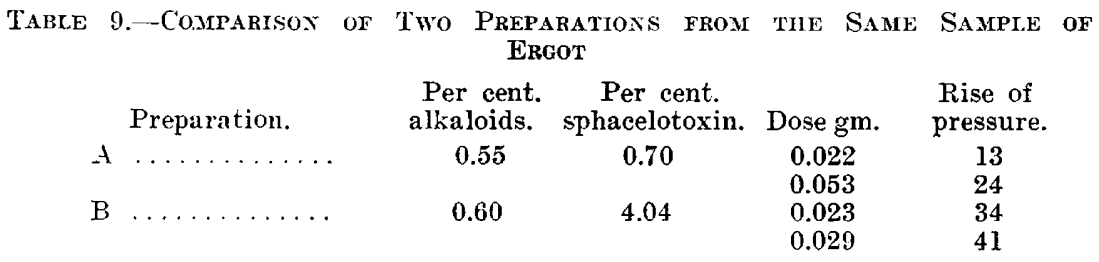

Further evidence of the value of this method of assay is derived from a study of the comparative activity of the matter extracted by benzol and the residue left behind after benzol extraction. In Table 10 are the protocols of three experiments made with different portions from fluidextract Cook No. 1. It will be seen, that while large doses of the watery residue produced a slight rise of the blood-pressure, the effect was in no way comparable to the strength of the whole fluidextract. Thus in Experiment 2, the injection of an amount of the marc of the fluidextract equivalent to $0.12 \mathrm{gm}$. of the original fluidextract produced a rise of 10 $\mathrm{mm}$.; $0.15 \mathrm{gm}$. more of the same preparations produced a maximum rise of $29 \mathrm{~mm}$. above the normal (we did not wait long enough to determine how well this rise would be maintained), but an injection of the benzol extract from the same preparation representing $0.15 \mathrm{gm}$. of ergot produced a maximum rise of $55 \mathrm{~mm}$. above the normal, or $26 \mathrm{~mm}$. above the point at which the injection was made.

The activity of a number of these watery residues in comparison with the activity of the whole fluidextract is presented in Table 11. 
HORATIO C. WOOD, JR.-CLARENCE A. HOFER

Table 10.-Activity of Watery Residues ti Comparison with That of

Time. Pressure.

Fluidext. Cook No.1.

\begin{tabular}{|c|c|c|}
\hline $\mathbf{0}$ & 97 & Inject watery residue equivalent to $0.15 \mathrm{gm}$. fluidextract. \\
\hline 1 & 105 & \\
\hline 4 & 97 & \\
\hline 15 & 100 & Inject $0.15 \mathrm{gm}$. more of watery residue. \\
\hline 16 & 108 & \\
\hline 19 & 100 & Inject benzol extract equivalent to $0.21 \mathrm{gm}$. fluidextract. \\
\hline 22 & 123 & \\
\hline 28 & 119 & \\
\hline 35 & 128 & \\
\hline
\end{tabular}

Cook. No. 1 .

\begin{tabular}{|c|c|c|}
\hline \multirow{2}{*}{\multicolumn{3}{|c|}{ Inject $0.12 \mathrm{gm}$. watery part. }} \\
\hline & 95 & Inject $0.12 \mathrm{gm}$, watery part. \\
\hline 2 & 105 & \\
\hline 4 & 105 & Inject $0.15 \mathrm{gm}$. more (watery part). \\
\hline 8 & 124 & \\
\hline 9 & & Inject $0.15 \mathrm{gm}$. benzol soluble. \\
\hline 10 & 150 & \\
\hline 12 & 145 & \\
\hline ok I & & \\
\hline 0 & 114 & Inject benzol extract-0.28 $\mathrm{gm}$. ergot. \\
\hline 2 & 142 & \\
\hline 5 & 140 & \\
\hline 6 & $\cdots$ & Inject benzol extract- $0.11 \mathrm{gm}$. ergot. \\
\hline 8 & 142 & \\
\hline 12 & 145 & \\
\hline 13 & 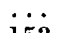 & Inject watery residue- $0.17 \mathrm{gm}$. ergot. \\
\hline 15 & 153 & \\
\hline 17 & 145 & \\
\hline 19 & 140 & \\
\hline
\end{tabular}

Table 11.-Activity of Watery Residles in Comparisox with that of FLUID Extract

Sample. Part used.

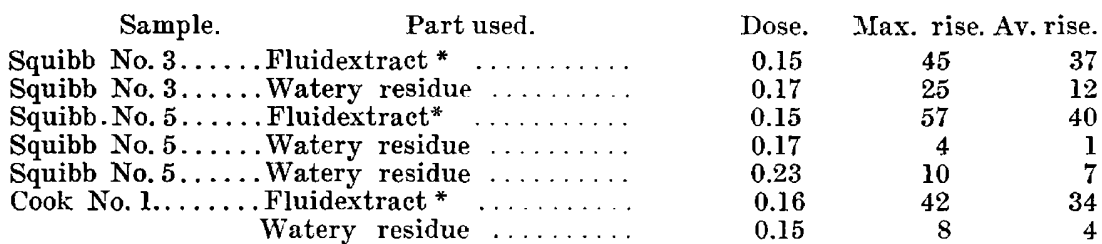

* Averages from Table 7 .

The possession of a slight degree of activity by the residue is not, in our opinion, a potent objection to the method. The United States Pharmacopeia recommends the assay of opium for its morphin, negleeting other active alkaloids which are present, and it must certainly be true that the residue left behind in the opium after extraction of the morphin is not entirely inert; in the same way, nux vomica is assayed for its strychnin, entirely orerlooking the presence of brucin. It is apparent, therefore, that chemical assay may be satisfactory even if a slight degree of potency remains in the marc. 
We have met, however, with a more serious objection to our method of chemical assay in testing preparations other than the fluidextract. For instance, Squibb sent us an experimental preparation of ergot which showed 0.45 per cent. of Keller cornutin and 0.21 per cent. of sphacelotoxin. This percentage of sphacelotoxin corresponds to physiological activity of about 10 , yet a dose of 0.16 c.c. of this sample produced a rise of $53 \mathrm{~mm}$. It is evident, therefore, that it is possible to obtain a watery solution of ergot which contains so large an amount of parahydroxyphenylethylamin, or some other principle, as to produce a considerable rise in the blood-pressure although the sphacelotoxin content may be very low; but also it is possible to obtain a preparation from opium, almost free from morphin, which would be highly depressant to the respiratory center through a large amount of codein. We would point out that while it may be possible to make watery preparations of ergot which will give, when tested by the blood-pressure method, high figures, yet such preparations are made at a great waste of ergot. For instance, the preparation just mentioned was supposed to be four times the strength of the fiuidextract, and yet when tested physiologically it was in the same class with an active fluidextract. In other words, there had been a loss of ergot amounting to $\% 0$ per cent. We have found that all those watery preparations which we have examined have been far below the strength which the manutacturers claimed for them.

Another exception to our assay method is in the case of preparations made with glycerin, as for instance, by the formula suggested by G. M. Beringer. ${ }^{25}$ We have examined two such preparations, one made by Mr. Beringer himself and the other by Professor Cook. One of these gave a physiological figure of 21 but yielded only 0.19 per cent. of sphacelotoxin. The other gave a rise in blood-pressure of $15 \mathrm{~mm}$. but only 0.08 per cent. of benzol extractive.

\section{CALSES OF TIIE POOR QUALITY OF FRGOT}

There has long been great dissatisfaction among clinicians with the quality of ergot which is available for practical use. Our investigations show that this distrust is well grounded. Of four preparations which we have obtained from the most reputable retailers in Philadelphia, the most active gave an average sustained rise of only $18 \mathrm{~mm}$; the other three gave respectively 10,11 and $5 \mathrm{~mm}$. If this is what may be expected from the better class of retail pharmacists, it is apparent that the fliidextract of ergot as ordinarily dispensed on prescriptions is nearly inert.

25. Beringer: Proc. Am. Pharm. Assn., 1908, lvi, 981. 
There are four possible causes for the lack of activity of commercial samples of preparations of ergot: (1) original inertness of the drug, (2) changes taking place in the crude drug, (3) improper methods of extraction, (4) changes taking place in the preparations after manufacture. We shall consider these four causes seriatim, and endeavor to find out the most important ones and to point out a remedy for the present undesirable condition.

As to differences in the activity of a fresh drug owing to possible influences of climate, soil, and so forth, our evidence is comparatively meager. It is so difficult to obtain authentic samples of the crude drug from different localities that it is almost impossible for investigators to accurately determine this point. Our sole evidence is based upon three samples of ergot. Through the courtesy of H. K. Mulford and Company, we were provided with a sample of German ergot and on $€$ of Spanish rergot. We found the Spanish more active than the German ergot.

As to the deterioration which takes place in crude ergot, this may be the result of one of two causes, the attacks of insects to which the drug is peculiarly liable, or spontaneous chemical changes taking place in the drug. Grinfeld tested a sample of crude ergot by the cock's-comb method at varying intervals. He found it required, in October, twice the dose that it did in August to produce the same degree of reaction, and that in February it required eight times this dose; in April twelve times the dose, and by the following June no dose would produce the reaction. This would indicate a deterioration in the first two months of keeping, at the rate of 6.2 per cent. a week; in the first six months of keeping, a rate of 3.5 per cent. per week; and in nine months of keeping, a rate of 2.8 per cent. a week. We attempted to make an investigation into this point, but owing to various obstacles, the results are of no ralue.

Grïnfeld does not mention how the ergot was kept, except that it was powdered. Although the experiments which we made as regards the keeping quality of crude ergot do not throw any light on the rate of deterioration, they are at least suggestive as to the influences of different methods of storing. On November 1, 1908, we received from Smith, Kline and French, a sample of fluidextract (marked in our tables as S. K. F. No. 1) and also a sample of the ground ergot from which this fluidextract was made. The ground ergot was divided into three portions, one of which was kept in a paper box, the second hermetically sealed in a glass bottle, and the third was dried for forty-eight hours at a temperature of $37 \mathrm{C}$. and then hermetically sealed. At the time this ergot was received we had not yet worked out our method for a chemical assay of the drug and the figures on this point are therefore lacking. 
The physiological test which was made of this fluidextract at the time it was received showed a rise of $47 \mathrm{~mm}$., but this figure is evidently too low, when taken in the light of the chemical studies later made of the ground ergot. The three samples of crude ergot were made up into fluidextracts by Professor Cook six months later and yielded the following percentages of sphacelotoxin:

Sealed, 0.81 .

Dried and sealed, 1.10 .

Kept in paper box, 0.93 .

These figures indicate that the best method of keeping crude ergot is to dry it at low temperatures and then to protect it from atmospheric influences by keeping it hermetically sealed.

If crude ergot loses strength as rapidly as the figures of Grünfeld indicate, it is evidently important to determine the length of time which ordinarily elapses between the harvesting of the ergot and its manufacture into fluidextracts. In the present condition of the ergot business, both in Europe and in this country, it is almost impossible to know definitely the age of any individual sample of ergot. Some of the larger manufacturers have their own agents in the ergot districts of Europe, and are therefore able to know within reasonable probability of the freshness of their supply; but the smaller manufacturers who have to rely on general importers of the drug are entirely at the mercy, first, of the European dealers, who will hold over from year to year any of the drug not sold immediately after its collection, and also of the jobbers in this country who sell, of course, any stock that they happen to have on hand. We have a sample of ergot, obtained from a London exporter by $\mathrm{H}$. K. Mulford \& Co., which was received in London in 1904, with the statement that it had been kept in cold storage for three years, and when it reached our hands in 1908, was therefore at least seven years old. It was thoroughly worm-eaten, but in its general appearance vaguely suggested ergot. In the letter which accompanied it, was the naive statement by the exporter that "if sifted, it would look presentable, but could be salable at current prices only if a scarcity came along or if wanted for a cutting contract for some institution."

As bearing on the quality of ergot which is made up into fluidextracts, it is interesting to note that of seven fluidextracts which were furnished us directly by the manufacturer, six reached a reasonable standard of activity; one specimen was practically inert.

Some years ago, Dr. E. H. Squibb had a fluidextract of ergot prepared by his firm, carried by a ship surgeon on a voyage around the world. and when, in the course of time it came back to him, he tested it 
clinically and eame to the conclusion that it was active. A similar observation to that of Dr. Squibb has been reported by Sharp ${ }^{26}$ with a liquidextract of the British Pharmacopeia, which he found active after twelve months. Largely on the basis of Dr. Squibb's observation, the belief is prevalent among pharmacists that the fluidextract of ergot is a stable preparation, and that the cause of the poor quality of the drug on the market is owing to changes in crude ergot before manufacture.

We would point out, lowever, that such evidence is practically worthless. In the first place, there was no definite knowledge of how active the preparation of ergot was when manufactured and in the second place, no reliable information as to the activity at the end of the year. Clinical tests cannot be considered as scientific evidence in such questions.

IVe have, moreover, very convincing proof that the fluidextract of ergot is fully as unstable, if not more so, than the crude drug. The evidence of this, as well as of some points which bear upon the causes of this change, are summarized in Table 12. In this table, the samples S. K. F. No. 1 and Squibb No. 2, were received from the manufacturers before the chemical method of assay was worked out and for purposes of accuracy in relative strengths we have much more confidence in our chemical assay than in any physiological test. The figures which are given for these two samples for the percentage of sphacelotoxin represent the theoretical per cent. that a preparation giving the corresponding physiological figures should contain.

The method of studying the rate of change which took place was as follows: As each new sample of fluidextract was received it was divided into three portions, one of which was hermetically sealed in a bottle from which practically all the air had been excluded; the second was put away in a bottle simply stoppered with cotton to keep out the dust, thus permitting free exposure to the air; the third bottle was used for immediate tests. This third jortion was opened from time to time to take out small quantities such as were needed, imitating (dosely therefore the conditions under which it would ordinarily remain on the pharmacist's shelf.

It will be noted that in the bottle exposed to the air, the loss of potency was comparatively rapid; in one case, as high as 5.5 per cent. each week, and in every instance the preparation had lost at least 50 per cent. of its active principle within a period of five months. On the other hand, those samples which were kept hermetically sealed lost their strength much more slowly; the most rapid of these, according to the

26. Sharp: Merck's Rep., November, 1908, p. 302. 
table, being that of S. K. F. No. 1, which deteriorated at the rate of 2.3 per cent. a week. This figure, however, is hardly fair, because the sample had been kept in a bottle which was opened at varions intervals for some two weeks before it was sealed; at the time of sealing this bottle the fluirextract gave, in two experiments which were made at that time, a plursiological activity of only 20, so that it is probable that change had already taken place in the preparation before it was removed from atmospheric influence. Leaving out this sample we find that the diminution in splacelotoxin content ranged from 0.2 to 1.1 per cent. a week. In the ases of those bottles which were corked, but from which the air was not entirely excluded, the loss of potency was, as might be expected. midway lotween the sealed and the open bottles, showing an average of about 2.6 per cent. a week.

Another preparation made for us by Professor Cook may be quoted. although owing to an unexpected pharmacentical problem the evidence is somewhat complicated. Professor Cook sent us, in May, a fluidextract, made according to the United States Pharmacopeia of 1880 and divided into two portions, one of which had been filtered after percolation, the other not. A portion of the unfiltered half, which contained 0.49 per rent. of sphacelotoxin, was sealed; the filtered portion which gave 0.34 per cent. was placed in an unstoppered bottle. Four months later, the sealed (unfiltered) gave 0.45 per cent. compared to 0.49 per cent. when iresh; the open bottle but 0.19 per cent., compared to 0.34 per cent. when fresh. It is interesting to note also that a bottle of the unfiltered sample which had been kept corked, but not hermetically sealed, gave at the same late 0.24 per cent. of benzol extractive.

Mable 12.-Test of Frcinextract of Ekgot (Cook No. 2 ) Cxink Vartous Condtioxs of lireshress and Expostre

Filtered. $\quad$ Lnfiltered.

$\begin{array}{llrl}\text { Fresh } \ldots \ldots \ldots \ldots \ldots \ldots & 0.34 \% & 0.49 \% & \\ \text { Sealed } \ldots \ldots \ldots \ldots \ldots & 0.43 \% & 21 \text { weeks old. } \\ \text { Corked } \ldots \ldots \ldots \ldots \ldots & 0.24 \% & 0.37 \% & 21 \text { weeks old. } \\ \text { Open } \ldots \ldots \ldots \ldots \ldots \ldots & 0.18 \% & \ldots \ldots & 21 \text { weeks old. }\end{array}$

The evidence quoted above as to the changes which take place in the fluidextract of ergot throw much light on the causes of the poor quality of drug which is found in the retail market. In onr opinion. the inertness of a retail fluidextract of ergot is due chiefly to the length of time elapsing between the manufacture of the fluidextract and its sale to the patient. Manufacturers are in the habit of storing away their fluidextract for varying periods of from three to nine months, in order to allow it to settle and become clarified. It then goes to the joblser. who 
may store it for another six months or a year; it reaches the pharmacist at least one, and generally two years old, and stays on his shelf perhaps another year or two before it is dispensed to the patient. While a tightly corked bottle is almost hermetically closed, so that the fluidextract as stored by the manufacturer is protected against the deleterious influence of the atmosphere, it must nevertheless be remembered that the loss of strength, even in sealed bottles amounts to nearly 50 per cent a rear on the average. It is evident, therefore, that it cannot be expected that a sample of fluidextract of ergot which has been kept for two or three years, even under the most farorable conditions, can possess a great deal of physiological power.

One other factor of importance from a pharmacentical standpoint deserves mention, and that is the means which are used for extracting the activities from the drug. If our belief is correct that the most active ingredient of ergot is sphacelotoxin, it is evident that no watery preparations of ergot can thoroughly represent the drug. It is, of course, conceivably possible that by an elaborate process of manufacture, the sphacelotoxin could be decomposed and the alkaloid hydro-ergotinin obtained. This alkaloid, however, is itself almost insoluble in water, and according to Barger and Carr, the salts which it forms with the inorganic acids are likewise but slightly soluble, so that even by extracting the alkaloid in the free state, we can hardly hope to obtain a highly active preparation of ergot. Our experiments with various watery preparations of the drug hear out this deduction. We have tested physiologically three samples of this class of preparations, two of which are on the market and recommended for hypodermic administration, the third being an experimental product which was sent us by the manufacturer, who was attempting to obtain an active watery preparation of ergot. Not one of these three samples equaled the figures which were claimed for them by the maker. Two of then were almost absolutely inert, and the third, the label of which bore the statement that 1 c.c. equaled 4 gm. of ergot, was of about the strength of an ordinary fluidestract.

Our conclusions as regards the quality of ergot which is at the disposal of the physician may be summed up as follows:

1. Preparations of ergot obtained from retail pharmacists are almost universally far below the standard.

2. No preparation of ergot which does not contain considerable amounts of alcohol or some similar inorganic solvent can thoroughly represent the drug. 
3. Starting with an active specimen of crude drug, a fluidextract freshly made, according to the process of the eighth revision of the United States Pharmacopeia, will furnish a potent preparation.

4. Both the crude drug and fluidextract deteriorate comparatively rapidly.

5. We would recommend, therefore, that all preparations of ergot should bear on the label the date of their manufacture, or at least the date beyond which the strength of the specimen cannot be trusted, as do the antitoxic serums, and should be preserved in small bottles, hermetically closed.

Table 13.-.-Loss of Stresgiti of Ergot by Keeping

How kept. Physiological $\begin{gathered}\text { How long kept Loss per week } \\ \text { Test. Sphacelotoxin. wks. }\end{gathered}$

S. K. F. No. 1 .

\begin{tabular}{|c|c|c|c|c|}
\hline Fresh $\ldots \ldots \ldots \ldots$ & 47 & $.70^{*}$ & & \\
\hline Sealed $\ldots \ldots \ldots \ldots$ & 25 & 0.48 & 14 & 2.3 \\
\hline Corked $\ldots \ldots \ldots \ldots$ & 19 & 0.35 & 14 & 3.6 \\
\hline
\end{tabular}

S. K. F. No. 2.

$\begin{array}{lllll}\text { Fresh } \ldots \ldots \ldots \ldots \ldots \ldots & \mathbf{6 3} & 1.05 & \ldots & \ldots \\ \text { Sealed } \ldots \ldots \ldots \ldots \ldots & \mathbf{3 9} & 0.78 & \mathbf{2 2} & 1.1 \\ \text { Corked } \ldots \ldots \ldots \ldots \ldots & 1 & 0.73 & 22 & 1.4 \\ \text { Open } \ldots \ldots \ldots \ldots \ldots & 14 & 0.45 & 20 & 2.8\end{array}$

Squibb No. 2.

\begin{tabular}{|c|c|c|c|c|c|}
\hline & & & & & \\
\hline Fresh & $\ldots \ldots \ldots$ & 37 & $0.60^{*}$ & & \\
\hline Sealed & $\ldots \ldots$ & 40 & 0.59 & 7 & 0.2 \\
\hline Corked & $\ldots \ldots \ldots \ldots$ & $\ldots$ & 0.45 & 25 & 1.0 \\
\hline Opened & $\ldots \ldots \ldots \ldots$ & 19 & 0.37 & 7 & 5.4 \\
\hline
\end{tabular}

( ook No. 1 .

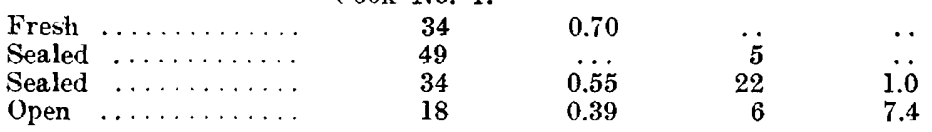

( ook No. 3 .

$\begin{array}{llrr}\text { Fresh } \ldots \ldots \ldots \ldots \ldots \ldots \ldots & \ldots .93 & \\ \text { Corked } \ldots \ldots \ldots \ldots \ldots \ldots \ldots & 0.80 & 5 & 2.8 \\ \text { Corked } \ldots \ldots \ldots \ldots \ldots \ldots & 0.54 & 13 & 3.2\end{array}$

Cook No. 4.

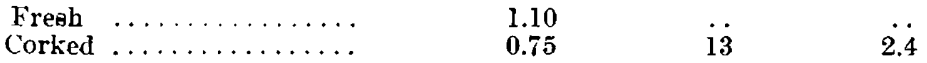

Squibb No. 4.

\begin{tabular}{|c|c|c|c|c|}
\hline Fresh & . & 0.95 & & \\
\hline Corked & $\ldots \ldots \ldots \ldots \ldots$ & 0.69 & 12 & 2.3 \\
\hline Sealed & $\ldots \ldots \ldots \ldots \ldots \ldots$ & 0.70 & 12 & 2.2 \\
\hline
\end{tabular}

Experimental.

Fresh $\ldots \ldots \ldots \ldots \ldots \ldots$

Corked $\ldots \ldots \ldots \ldots \ldots \ldots \ldots \ldots \ldots \ldots \ldots$

* Estimated from the physiological figure. 
SUMMARY

The important facts brought out in this paper may be summarized as follows:

1. Ergot is a stimulant to all the unstriped muscle tissue of the body.

2. As a part of this general action there is a stimulant effect on the arterial muscles and probably also on the heart.

3 . The action on the blood-vessels occurs after destruction of the vasomotor center and must be, therefore, the result of an effect on some portion of the peripheral vasomotor mechanism.

4. The degree of elevation of blood-pressure affords an accurate criterion of the activity of ergot and is, in our opinion, the most available method for the biological assay of the drug.

$\tilde{5}$. The active principle of ergot is an alkaloidal substance which occurs in the drug probably in chemical union with a resinous body. For the combination we suggest the retention of the name suggested by Jacobi of sphacelotoxin and for the alkaloidal substance the term applied by Kraft of hydro-ergotinin.

6 . The percentage of sphacelotoxin varies accurately with the physiological activity of different specimens of ergot.

7. The percentage of sphacelotoxin in a fluidextract may be easily estimated by precipitating with water and extracting with benzol.

8. A fluidextract of ergot exposed to the air deteriorates extremely rapidly.

9. The deterioration of fluidextract of ergot may be much retarded by protecting it against contact with the air, but under the most farorable conditions there is a loss of strength approximatlng 10 per cent. a month. 434 South Forty-fourth Street-5006 Cedar Arenue. 